\title{
Designing and Implication of Pictograms in Universities of Tehran (IRAN)
}

\author{
Firouzeh Keshavarzi ${ }^{1,2,}$, Hamedi Mohd Adnana ${ }^{1, * *}$ \\ ${ }^{1}$ Department of Media Study, Faculty of Arts and Social Sciences, University of Malaya, 50603 \\ Kuala Lumpur, Malaysia. \\ ${ }^{2}$ Department of Graphic Design, College of human science, Islamshahr Branch, Islamic Azad \\ University, Tehran, Iran.
}

\begin{abstract}
Pictograms have many implications nowadays and are used for simple and fluent pictorial interpretations. These concepts are usually informative, conductive and warning. These kinds of icons are used in order to simplify the communication in an environment as are used in airports, terminals, railroad stations, parks, zoo, hospitals, drug stores and so on. To provide an efficient contrast, pictograms are often in black and white. Nowadays in different public places and landscape design pictograms are used for perfect communication. By the ways these icons are related to the civilization and tribal culture. Designing pictograms need a permanent search for better plan for better information transfer. In this project researcher designed and executed pictograms for better conduction in some selected Universities in Iran at 2015. The project was done for internal and external places of selected universities. Absence of informative and pictorial icons in universities environments causes wandering about for novices and they are not able to find different places like libraries, restaurant, and offices and so on. This study resulted in better communication in campus environments. Researcher hope pictograms will find their real and proper role in Iranian art area.
\end{abstract}

\section{Introduction}

Pictograms are a group of signs which are used greatly nowadays in public places. In fact, pictography is a kind of writing ideas with drawings [1]. 5000 years B.C. Chinese used pictogram to communicate. These signs are used by Indians, African and etc... [9]. In 1937 London underground used pictograms. Nowadays these are commonly used for restrooms, restaurant and railway stations [2]. In early 1980's pictograms were used to communicate with low educated persons in public places. A form of worldwide pictograms is related to cloths (washing, ironing and so on). Pictograms about chemical hazards are another form of these signs [10].

Point pictograms are composed of 50 shapes which are mainly used by travellers through public places. These kinds of signs are mainly used in airports, hotels, stations and

\footnotetext{
* Corresponding author: keshavarzi@um.edu.my

** hamedi@um.edu.my
} 
other public places. In fact, one of the main aims of pictograms is an efficient conduction. If this icon works perfectly there will be no need to employ some persons in information centres [4].

Pictograms are simplified icons which are somehow related to the main idea. There are some difficulties and disadvantages for pictograms too, for example pictograms on medicine are effective for medium- educated persons [8].

Communication is mainly based on person's visual intellect. Recent researches show that visual intellect is related to ecological, cultural and environmental factors. In designing pictograms, the target group is very critical [7] Pictograms by conducting a concept in a small pictorial form cause beauty of environment. Lemmom \& Hyman 2006 believed that pictograms should be standardized to lower the dangerous results of some pictorial especially in medical usages [6].

Davies at al 1998 found that some pictograms are not totally understood by target group in Europe [3]. Katri et al. 2004 studied groups of children as target group for concepts which were presented by Pictograms on Medicines [5].

They found most kids new them perfectly. No research has been done in educational environments as schools and universities about pictograms. In this research, researcher tries to make pictograms for a campus environment in order to lesser the problems of newly arrived students while searching for different parts of our university [7].

\section{Materials and Methods}

Projects were done in a campus environment about $18000 \mathrm{~m} 2$ from 2014 to 2015 . For the first step researcher draws many design with different colours. Some of these plans were composed of Iranian design. Researcher test many materials and colours to find the best one. Some of these plans were composed of Iranian design. Researcher test many materials and colours to find the best one.

This study uses mixed methods for collecting and analysing data; qualitative and quantitative methods can help the study complete its aims. Searching documents, the study surveys some previous researches in library and databases about designing and implication of pictograms in Tehran (Iran). Observation is another way of quantitative method for collecting data which study applies it. In this way study deals with looking at current designing and implication of pictograms and seeking their universities design. Interview, observation and questionnaire are other ways which this study uses.

\section{Results}

Pictograms are an effective way to communicate. These should be easily understood too. Researchers design some pictograms for open places and landscapes of universities. Researchers consider the education level of my target group and try to make pictograms which are concordant with their educational level. Researcher try to simplify pictograms while no part of essential information omitted. Designed pictograms were used for each faculty. Stories pictograms were homogenized (in form and colour) with open environment pictograms.

For construction of pictograms different materials were examined. Plexiglas is affected by light, cold and climatic conditions. These cause Plexiglas to be darken. So researcher use galvanized iron plate which has the most resistant material.

Pictograms were designed due to the theme of each parts of university. Designed elements were composed with the Icon of University Logo to find a beautiful and pleasant form. 
Colour was very important in this project. The colours were chosen in accordance with the university logo so researcher tries to make different composition between different forms and colour to find an efficient composition.

\section{Discussion}

After using these pictograms, the university environment changed to be very pleasant. There was no need for information both. In the beginning of the semester, students easily find their ways and their questions were answered indirectly. Other university can use our patterns or their own ones to communicate with their target groups. In this project pictogram is used and proposed in universities for the first time it was previously used for public places. These pictograms were used for university restaurant, telephone booth, Mosque, Library, security, entrance and so on. Without these universities should employ some officer to help people find their way. The university should pay a lot for these people. Novice has many problems when they enter a university for the first time. Pictogram are efficient way to find way and have a better understanding of environment. Graphic designs are efficient way to make the environment more pleasant. Typical design of pictograms for Islamic Azad University in Tehran (Figure1).

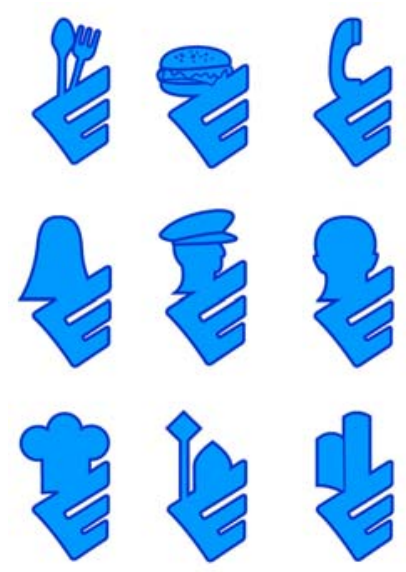

Fig. 1. Pictograms designed for different parts of the Islamic Azad University in Tehran.

\section{References}

1. A. Mosavilar, Pictograms. Jelve Honar (8 \&9): (in Persian, 1997)

2. Anonymus. The Professional Association for Design for the U.S. Department of Transportation. Symbol signs, 2nd Ed. New York: American Institute of Graphic Arts (1993)

3. S. Davies, H. Haines, B. Norris and J. R. Wilson. Safety pictograms: are they getting the message across?, Appl. ergonomics 29, 1 (1998)

4. E.Lupton,J.A. Miller,Design Writing Research: Writing about Graphic Design. New York: Kiosk (1996)

5. H.Katri, K.Kati,E.Hannes, J. Patricia,M. Airaksinen, Do pictograms improve children's understanding of medicine leaflet information? Patient Educ. \& Couns. 55, 3 (2004)

6. H.Lemmon, W.Hyman,Pictowhat? Problems with the Use of Pictograms on Medical Devices. J.Clin. Eng., 31, 4 (2006) 
7. M.S.Ehlers, R.Dowse, Guidelines for the design of culture-specific pharmaceutical pictograms for use in a South African population. Int J Pharm Pract, in press (2007)

8. R.Dowse,M.S.Ehlers, The evaluation of pharmaceutical pictograms in a low-literate South African population. Faculty of Pharmacy, Rhodes University, Grahamstown 6140, South Africa, 45, 2 (2001)

9. R.Dowse, M.S. Ehlers, The development and evaluation of pharmaceutical pictograms. In: Scott PA, Bridger RS, J. Charteris, editors. Global ergonomics. Proceedings of the Ergonomics Conference, Cape Town. Amsterdam: (1998)

10. R.Dowse, M.S. Ehlers, Pictograms in pharmacy. Int. J. Pharm. Pract. 6, (1998) 